\title{
Limitations of Probiotic Therapy in Acute, Severe Dehydrating Diarrhea
}

\author{
*Hugo Costa-Ribeiro, *Tereza Cristina M. Ribeiro, *Angela P. Mattos, *Sandra S. Valois, \\ *Daniela A. Neri, *Patricia Almeida, *Celina M. Cerqueira, *Eduardo Ramos, \\ $\dagger$ Rosemary J. Young, and †Jon A. Vanderhoof
}

Department of Pediatrics, School of Medicine, *Federal University of Bahia Salvador, Bahia, Brazil and $\dagger$ University of Nebraska Medical Center, Omaha, Nebraska, U.S.A.

\begin{abstract}
Background: Recent studies have shown that probiotics, most commonly Lactobacillus GG, may be useful in treating acute gastroenteritis. However, beneficial effects appear to be limited to a modest decrease in the duration of diarrhea. No studies have evaluated this therapy in moderate to severe dehydrating diarrhea in a metabolic facility.

Methods: Male children less than 2 years of age were admitted to a metabolic unit of the Department of Pediatrics at the Federal University of Bahia, Brazil, with moderate dehydration and were randomized in a double-blind, placebo-controlled fashion. Oral rehydration solution (ORS) was administered per protocol and either placebo or Lactobacillus $G G$ was given in combination with the ORS. Output of urine, stool, and vomitus was recorded along with stool weight, nude body weight, and standard laboratory assessments for hydration.
\end{abstract}

Results: There was no significant reduction in diarrhea duration and stool output in the Lactobacillus $G G$ group. However, Kaplan-Meier survival analysis demonstrated that, even in moderate to severe diarrhea, resolution of the illness occurred so rapidly, that statistically significant benefits of probiotic therapy could not be demonstrated.

Conclusion: Our data implies that colonization must occur before benefits of probiotics can be realized. Probiotics are, therefore, likely to be of limited benefit in treating diarrheal illnesses of short duration such as viral enteritis. The beneficial effects of probiotics may be limited to prophylactic usage in high-risk populations. JPGN 36:112-115, 2003. (C) 2003 Lippincott Williams \& Wilkins, Inc.

\section{INTRODUCTION}

Worldwide, diarrhea is the number one cause of mortality in children less than 5 years of age (1). Mortality is highest in developing countries where sanitation is poor. In the industrialized world, death from diarrheal illness is uncommon and hospitalization is infrequent (2).

Lactobacillus casei subspecies rhamnosus (LGG) has been shown to reduce the duration of common viral diarrheal illness in a large multicenter study in Europe (3). Potential benefit of LGG in moderate to severe diarrhea (greater than $5 \mathrm{ml} / \mathrm{kg} / \mathrm{h}$ stool output) and dehydration (loss of greater than $10 \%$ body weight) in a tropical

Address correspondence to Jon A. Vanderhoof, University of Nebraska Medical Center, 985160 Nebraska Medical Center Omaha, NE 68198-5160, U.S.A. (e-mail: jvanderh@unmc.edu).

At the time of submission of this manuscript, Dr. Vanderhoof was Vice President of Nutrition and Health Sciences at ConAgra Foods, Inc., which is the sole distributor of Lactobacillus GG in North America. Previous studies of Dr. Ribeiro have been supported by ConAgra Foods. developing country has not been evaluated. We therefore evaluated the hypothesis that LGG might reduce the severity and duration of diarrhea in a double-blind, placebo-controlled trial in hospitalized children in northern Brazil.

\section{PATIENTS AND METHODS}

Males, aged 1 to 24 months, with acute diarrhea (defined as three or more watery or loose stools per 24 hours during at least one 24-hour period in the 72 hours before admission) with signs of moderate dehydration by the World Health Organization (WHO) criteria (Table 1) were included in the study. If severe dehydration was present, rapid IV hydration was completed before randomization. Children with severe malnutrition ( $<$ or equal to $65 \%$ of the weight for age by the standards of the National Center for Health Statistics), children with systemic infections requiring antibiotics, and children with bloody diarrhea were excluded. It is recognized that in children with acute watery diarrhea treated with the WHO/UNICEF oral rehydration solution, stool output is highly variable. The standard de- 
TABLE 1. Assessment of dehydration (WHO criteria)

\begin{tabular}{llll}
\hline & A & \multicolumn{1}{c}{ B } & \multicolumn{1}{c}{ C } \\
\hline Condition & Normal & Irritable & Lethargic/comatose \\
Eyes & Normal & Sunken & Very sunken \\
Thirst & Normal & Thirsty & Unable to drink \\
Skin turgor & Normal & Reduced & Very reduced \\
Capillary refill & $<2$ secs & $2-3$ secs & $>3$ secs \\
\hline
\end{tabular}

Dehydration status

$\mathrm{A}=$ no dehydration

$\mathrm{B}=$ moderate dehydration $(2$ signs coded in column $\mathrm{B})$

$\mathrm{C}=$ severe dehydration $(2$ signs coded in column $\mathrm{C}$ )

viation of the mean total stool output is approximately equal to the mean stool output. Therefore, the equation for sample size calculation based on hypothesis testing for 2 population means (one-sided test), assuming a significance level of 5\%, with $80 \%$ power to detect a $25 \%$ reduction in mean stool output per hour suggested that 57 children would be needed per treatment group (4). Since the patients were all inpatients admitted to the metabolic unit, only a $5 \%$ dropout rate was expected.

The study was conducted in a 16-bed metabolic unit of the Department of Pediatrics at the Federal University of Bahia where about 1,000 children who would fulfill the eligibility criteria are admitted annually. The ethical review panel of our study center approved the study and informed consent of the parents was obtained. Baseline examination was conducted to determine eligibility. Initial data collected included symptoms before admission, previous treatments attempted, changes in feeding methods before admission, and results of biochemical and microbiologic data. Those children determined to have at least moderate dehydration were randomized as assigned by a code administered sequentially. To facilitate separation of urine from stool, only male infants were included. Both placebo and LGG were packaged in identical capsules and in foil wrapping to prevent moisture infiltration. Powder in both types of capsules was identical in texture and color and when administered was combined with the oral electrolyte solution. The LGG dose was 10 billion colony-forming units (CFU's) per day. LGG capsules contained a small amount of inulin $(320 \mathrm{mg})$ to facilitate packaging; the placebo contained inulin alone.

Oral rehydration solution was administered at $100 \mathrm{ml} / \mathrm{kg}$ over 6 hours with an interval evaluation of the hydration status at 3 hours. If the child wanted more than the estimated amount of fluid and no signs of overhydration were present, the child was allowed more ORS. Breast-feeding was continued ad libitum during this time. Cow milk formula, water, and other foods were withheld during the rehydration phase.

Maintenance phase therapy was initiated at the end of the rehydration phase and continued until cessation of diarrhea (passage of 2 semi-formed or formed stools or no stool for 24 hours) or day 7, whichever came first. During this phase, stool losses (by weight) were replaced with an equivalent volume of ORS solution. Infants aged 1 to 4 months continued breastfeeding and those infants receiving fewer than 5 breastfeeds a day were given $55 \mathrm{cal} / \mathrm{kg} / \mathrm{d}$ of cow milk formula. Non-breastfeeding infants were offered $110 \mathrm{cal} / \mathrm{kg} / \mathrm{d}$ in 8 feedings. Those infants 5 to 24 months of age receiving partial breast-feeding also were given $75 \mathrm{cal} / \mathrm{kg} / \mathrm{d}$ of cow milk formula and/or a rice-based diet according to breast milk intake. Older nonbreast-fed infants were offered $110 \mathrm{cal} / \mathrm{kg} / \mathrm{d}$ of cow milk formula and/or rice-based diet in 6 feeds per day. During the rehydration phase, worsening of diarrhea while receiving oral rehydration or no improvement within the first 6 hours resulted in intravenous fluid therapy. These children remained in the study. Children with diarrhea lasting longer than 7 days were removed from the study.

Stool weight was measured using metabolic beds designed for the collection of all stool excreted. All urine volume was measured with standard urine collection bags and vomitus weight was measured using pre-weighed pads. Total fluid intake was recorded throughout the duration of the diarrhea. Nude body weight was measured on admission, after rehydration, daily, and on discharge. Body length was measured on a standard length board to the nearest $1 \mathrm{~cm}$. Standard laboratory measures for serum sodium, potassium, hematocrit, and urinespecific gravity were taken at randomization and at 24 and 48 hours after randomization. The presence of rotavirus and glucose in the stools was assessed with ELISA and Clinitest kits respectively. All information was recorded on the standard data collection forms.

Outcome variables are identified in Table 2. The means (+ SD) of growth parameters, vital signs, and laboratory values were compared using box and whisker plots, including outliers. The log, transformed stool volume, and ORS intake were expressed as geometric means with $95 \%$ CI. The ratio of the geometric means was used to compare treatment groups. For variables with normal distribution, results were expressed as mean $(+\mathrm{SD})$ and comparison was made using Student's $t$ test.

\section{RESULTS}

One hundred twenty four infants, median age 11 months in the treatment group and 9 months in the control group, were enrolled. Median duration of diarrhea before admission was 48 hours in both groups. Mean stool output was $139.74 \mathrm{ml} / \mathrm{kg}$ in the treatment group and $184.63 \mathrm{ml} / \mathrm{kg}$ in the control group. Patients are described in Table 3. There was no difference in previous treatments, biochemical, or microbiologic data between groups. There were no differences between groups in the amount of ORS consumed or volume of breastfeeding. IV hydration was required in $13 \%$ in the LGG group and in $10 \%$ in the control group (NS). There was no significant reduction in the duration of diarrhea or stool output in the group taking Lactobacillus $G G$ versus the control group (Table 4). No patient had an episode of diarrhea lasting more than 7 days. Fifty two percent of the treatment group and $48 \%$ of the control group were rotavirus positive (NS). We separately evaluated the rotavirus positive patients and again found no significant

TABLE 2. Outcome variables

Duration of diarrhea (hrs) from time of randomization till cessation of diarrhea*

24-hr stool output ( $\mathrm{g} / \mathrm{kg}$ admission body wt) from the time of randomization

Total stool output ( $\mathrm{g} / \mathrm{kg}$ admission body wt) from randomization till cessation of diarrhea

Proportion of kids in each group requiring unscheduled IV infusion

Proportion of kids in each group vomiting during first $24 \mathrm{hrs}$ after randomization

Proportion of kids in each group with hyponatremia $24 \mathrm{hrs}$ after randomization

\footnotetext{
* Primary outcome variable.
} 
TABLE 3. Clinical features of male infants on admission

\begin{tabular}{lcc}
\hline & $\begin{array}{c}\text { Treatment group } \\
(\mathrm{N}=61)\end{array}$ & $\begin{array}{c}\text { Control group } \\
(\mathrm{N}=63)\end{array}$ \\
\hline $\begin{array}{c}\text { Age (months) } \\
\text { Median } \\
(\mathrm{P} \text { 25 P 75) }\end{array}$ & 11 & 9 \\
$\begin{array}{l}\text { W/H (z-score) } \\
\text { Median } \\
\text { (P 25 P 75) }\end{array}$ & $(717)$ & $(717)$ \\
$\begin{array}{c}\text { Diarrhea before } \\
\text { admission (hours) }\end{array}$ & -1.22 & -1.13 \\
$\begin{array}{l}\text { Median } \\
\text { (P 25 P 75) }\end{array}$ & $(-1.87-0.62)$ & $(-1.63-0.43)$ \\
$\% \begin{array}{c}\text { with moderate-severe } \\
\text { dehydration by WHO } \\
\text { criteria }\end{array}$ & $(3072)$ & 48 \\
\hline
\end{tabular}

differences between treated and placebo groups with respect to stool output or duration of diarrhea.

Figure 1 shows the duration of diarrhea expressed as KaplanMeier survival curves. It is obvious that there is no difference between the two groups $(P>0.1)$.

\section{DISCUSSION}

Treatment of acute diarrheal disease has advanced significantly in recent years. Utilization of oral rehydration solutions has made a major impact on morbidity and mortality especially in developing countries (5). Optimization of the standard WHO-ORS solution, by reducing osmolarity, has been shown to reduce diarrhea duration, total stool output, and the need for unscheduled IV therapy (6-8).

Probiotics would seem to be an ideal means to treat infectious diarrhea but have only recently been studied in
TABLE 4. Clinical data of hospitalized patients

\begin{tabular}{lccc}
\hline & Treatment & Control & $P$ value \\
\hline Diarrhea duration (hrs) & & & \\
Mean \pm SD & $38.27 \pm 3.78$ & $39.09 \pm 4.60$ & 0.59 \\
Median & 24.75 & 24.83 & \\
p25 - p75 & $18.33-54.41$ & $15.00-56.66$ & \\
Stool output/kg & & & \\
Mean \pm SD & $139.74 \pm 171.16$ & $184.63 \pm 274.13$ & 0.81 \\
Median & 67.68 & 56.05 & \\
p25 - p75 & $24.84-183.57$ & $23.96-173.96$ & \\
\hline
\end{tabular}

Kraskal-Wallis non-parametric test.

acute diarrheal disease. Numerous bacteria have been evaluated, including Lactobacillus reuteri, bifidobacteria, and certain strains of Lactobacillus acidophilus (9). The most thoroughly studied is Lactobacillus casei subspecies rhamnosus (LGG). These human-derived organisms appear to enhance systemic immune function (1011). They also promote mucin secretion (12). Both of these mechanisms would appear to be protective against ongoing injury and, therefore, result in more rapid resolution of the inflammatory process. In previous studies, Lactobacillus $G G$ has been shown to be effective in reducing both the duration and severity of acute, nondehydrating viral enteritis (13). In most studies, the beneficial effect of Lactobacillus $G G$ appears to be primarily a modest shortening of the duration of the illness.

We were unable to duplicate these previous studies in our population of more severely affected children in a metabolic unit. In our study we measured more quantitative endpoints rather than subjective reports of stool quantity and consistency. Consequently, our observations are possibly more valid in this early phase of viral diarrhea. Despite the more severe diarrhea and dehydration in our patients, the duration of the illness we ob-

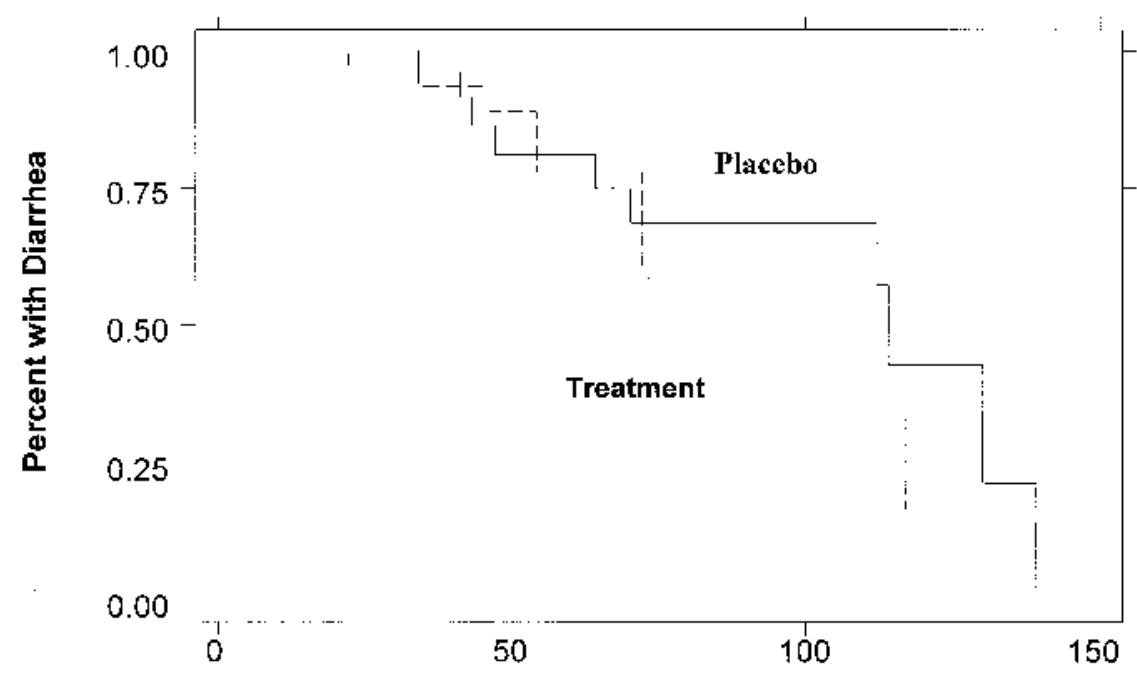

Analysis time (hours)
FIG. 1. Duration of diarrhea as depicted by Kaplan Meier survival estimates here, $P>0.1$. 
served was still quite short. Duration of diarrhea in the rotavirus positive children in Guandolini's study who received probiotic was 3 days while $11 \%$ of children in the placebo group had diarrhea for more than 7 days (3). It is likely that our patients were considered recovered during the convalescent phase of the illness, which may have been included in the duration of diarrhea this previous study.

Consistent with this hypothesis, the Kaplan-Meier representation of our data suggests that any beneficial effect of probiotics may be limited to a subpopulation of children who are likely to experience a protracted course of infectious enteritis. One might theorize that this relates to the necessity of colonization of the gut before a therapeutic effect. Indeed, the graph in Figure 1 suggests that the duration of illness curves began to separate between groups once colonization had been established. Unfortunately, there were too few patients with protracted illness in our study to allow evaluation of this possibility. Following the administration of a probiotic such as Lactobacillus $G G$, the organism must activate, proliferate, and colonize before it can alter mucin gene expression or enhance an antibody response against the offending virus. Any potential anti-inflammatory effect will not occur before colonization. Consequently the beneficial effects of the probiotic would not occur until 2 to 3 days after initial administration. This might also explain why the major benefit of LGG in previous studies was shortening the duration of the diarrheal illness.

Our results cannot be explained by other differences between groups. The percentage of rotavirus positive patients was comparable between groups and the severity of diarrheal illness was not different between groups. None of the patients admitted to the study had physical evidence of pre-existing chronic malnutrition, although micronutrient levels were not assessed. The LGG preparation remained stable throughout the study as determined by verification of capsule colony counts at the conclusion of the study. Previous studies have suggested that LGG is mainly beneficial in rotavirus diarrhea which constituted only about half of our patients.

Our study suggests that the major beneficial effects of probiotic administration will likely be observed with prophylactic usage in high-risk populations. Children living in areas endemic with diarrheal disease, children attending daycare, or travelers in countries with a high incidence of infectious diarrhea have all reported benefit from Lactobacillus GG (14-16). Further studies must be conducted to identify the exact situations and the se- lected organisms that might be of greatest benefit in these settings.

Acknowledgment: This study was supported in part by a grant from Pronex/CNP $(661086 / 1998-4)$, Brazil.

\section{REFERENCES}

1. Hirschhorn N. The treatment of acute diarrhea in children. A historical and physiological perspective. Am J Clin Nutr 1980;33: 637-63.

2. Bern C, Martines J, de Zoysa I, Glass RI. The magnitude of the global problem of diarrhoeal disease: a ten-year update. Bull WHO 1992;70:705-14.

3. Guandalini S, Pensabene L, Zikri MA, et al. Lactobacillus GG administered in oral rehydration solution to children with acute diarrhea: A multicenter European trial. J Pediat Gastroenterol Nutr 2000;30:54-60.

4. World Health Organization. Sample Size Determination in Health Studies: A Practical Manual. Geneva: WHO, 1991.

5. Snatosham M, Keenan EM, Tullock J, Broun D, Glass R. Oral rehydration therapy for diarrhea: an example of reverse transfer of technology. Pediatrics 1997;100:E10.

6. Alan NH, Majumder RN, Fuchs GJ, Ribeiro, Jr., HC, Bhan MK, Chea-Woo E, Fontaine O. Efficacy and safety of oral rehydration solution with reduced osmolarity in adults with cholera: a randomized double-blind clinical trial. Lancet 1999;354:296-99.

7. Ribeiro, Jr., HC, Alan NH, Majumder RN, Ruchs GJ, Bhan MK, Chea-Woo E, Fontaine O. Multicenter, randomized, double blind clinical trial to evaluate the efficacy and safety of a reduced osmolarity oral rehydration salts solution. Pediatrics 2001;107: 613-18.

8. Bhan MK, Chea-Woo E, Ribeiro, Jr., HC, Fontaine O, Maulen. Multicentre evaluation of reduced osmolarity oral rehydration salts solution. Lancet 1995;345:282-85.

9. Vanderhoof JA. Probiotics: future directions. Am J Clin Nutr 2001;73(suppl):1152S-55S.

10. Isolauri E, Joensuu J, Suomalainene H, Luomala M, Vesikari T. Improved immunogenicity of oral D x RRV reassortant rotavirus vaccine by Lactobacillus casei GG. Vaccine 1995;13:310-12.

11. Jung LK. Lactobacillus GG augments the immune response to typhoid vaccination: a double-blinded, placebo-controlled study. FASEB J 1999;13:A872 (abstr).

12. Mack DR, Michail S, Wei S, McDougall L. Hollingsworth MA. Probiotics inhibit enteropathogenic $E$. coli adherence in vitro by inducing intestinal mucin gene expression. Am J Physiol 1999;276: G941-50.

13. Isolauri E, Juntunen M, Rautanen T, Sillanaukee P, Koivula T. A human Lactobacillus strain (Lactobacillus casei sp strain GG) promotes recovery from acute diarrhea in children. Pediatrics 1991; 88:90-7.

14. Oberhelman RA, Gilman RH, Sheen P, et al. A placebo-controlled trial of Lactobacillus GG to prevent diarrhea in undernourished Peruvian children. J Pediatr 1999;134:15-20.

15. Hilton E, Kolakowski P, Smith M, Singer C. Efficacy of Lactobacillus $G G$ as a diarrheal preventative in travelers. J Travel Med 1997;4:41-3.

16. Hatakka K, Savilahti E, Ponka A, Meurman JH, Poussa T, Nase L, Saxelin M, Korpela R. Effect of long term consumption of probiotic milk on infections in children attending day care centres: double blind, randomised trial. Brit Med J 2001;322:1327. 